\title{
Relation between Epworth Sleepiness Scale and O bstructive Sleep Apnea - A study conducted in PULSAR, KOLKATA
}

\author{
D. J. Roy, A. Bhattacharya, A. G. Ghosal, R. K. Das

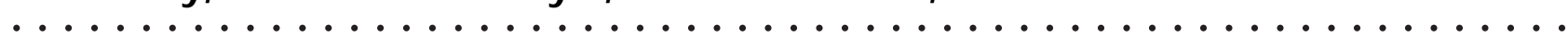 \\ Indian J Sleep Med 2006; 1.2, 93-96
}

\begin{abstract}
737 adult persons more than 18 years of age of both gender, randomly selected from Kolkata, were put to Epworth Sleepiness Scale (ESS)

See end of article for authors affiliations

questionnaire. $11.3 \%$ showed excessive daytime sleepiness (EDS) by ESS score. 74 polysomnographically diagnosed cases of obstructive sleep apnea (OSA), more than 18 years of age, showed presence of EDS in $81.1 \%$ of cases.

Address for correspondence:

Dr. D. J. Roy

PULSAR

264 C, Rashbihari Avenue,

EDS, as calculated from ESS score, has good predictive value in assessing OSA and may be used as a screening tool in diagnosis of OSA. The ESS score of the diagnosed cases showed positive association with moderate and severe OSA cases.
\end{abstract} Kolkata - 700019,

West Bengal, India.

Keywords: O bstructive sleep apnea, Excessive daytime sleepiness, Epworth sleepiness scale, Apnea - hypopnea index.

\section{Introduction}

0 bstructive sleep apnea (OSA) is characterized by repetitive episodes of upper airway obstruction that occur during sleep and is usually associated with a reduction in blood oxygen saturation with associated features of daytime sleepiness and snoring. ${ }^{1}$ Its importance has been recognized over the last two decades 2 . Snoring, apneic spell and sleep fragmentation are cardinal features. Excessive daytime sleepiness (EDS), fatigue, morning headache, loss of concentration, memory loss are some of the other associated clinical features ${ }^{3,4}$. EDS, one of the cardinal symptoms of OSA, is thought to result from sleep fragmentation due to recurrent central nervous system arousals in response to disturbed breathing events ${ }^{5}$.

Epworth Sleepiness Scale(ESS), a questionnaire-based scale, is used to assess individual propensity to sleepiness ${ }^{6}$. It describes individual's likelihood of dozing off at eight specific situations and scoring is done in each situation. M aximum total score possible is 24 (Table I). A total score of ten and above is considered to satisfy the criteria for excessive daytime sleepiness ${ }^{7,8,9,10}$.

Apnea-hypopnea (AHI) is one of the major criteria for diagnosis and measurement of severity of OSA. It includes total number of apneas and hypopneas per hour of sleep. Severity of OSA is graded as mild, moderate and severe according to AHI. AH I with 5-15, 15-30 and more than 30 per hour of sleep constitute mild, moderate and severe OSA respectively.

\section{Purpose of the study}

It is well known that the gold standard for diagnosis of $\mathrm{OSA}$ is polysomnography where measure of $\mathrm{AHI}$ is a criteria for diagnosis and grading of OSA. But it is costly and sparsely available in a country like India. ESS score which may predict a population with EDS (ESS score $\geq$ 10) would include a subset population of OSA in the ED S group. The present study wants to correlate the ESS score of polysomnographically diagnosed ( $\mathrm{AH} \mathrm{I}>5$ ) OSA cases with the ESS score of a control group in the general population. The study also attempts to relate severity of OSA with EDS by ESS score, if any.

Indian Journal of Sleep M edicine (IJSM ), Vol. 1, N o. 2, 2006 


\section{Material and Method}

1000 adult people (18 years and above) of both gender were randomly selected from Kolkata and were put to ESS questionnaire (Table 1).

Table 1: Epworth Sleepiness Scale

H ow likely are you to fall asleep or doze off in the following situations, during the daytime in contrast to just feeling tired ? These questions refer to your usual way of life in recent months even if you havenot done some of thesethings recently. Try to work out how they would have affected you.

U sethe following scale to choose the most appropriate number for each situation.

$0=$ Would never doze off

1 =Slight chance of dozing

2 =M oderate chance of dozing

$3=\mathrm{H}$ igh chance of dozing respectively (Table 2 ).

Table 2: D ata showing ESS score of 737 persons from Kolkata $n=737$

\begin{tabular}{|l|l|l|}
\hline & $\begin{array}{l}\text { N O ED S } \\
\text { (ESS <10) }\end{array}$ & $\begin{array}{l}\text { ED S } \\
\text { (ESS } \geq 10)\end{array}$ \\
\hline$n=737$ & $654(88.7 \%)$ & $84(11.3 \%)$ \\
\hline M ale : Female & $394: 260(1.5: 1)$ & $52: 32(1.6: 1)$ \\
\hline Age in years (M ean \pm SD ) & $47.3 \pm 11.5$ & $47.7 \pm 13.2$ \\
\hline BM I in $\mathrm{Kg} / \mathrm{M}^{2}(\mathrm{M}$ ean $\pm S D)$ & $24.7 \pm 2.1$ & $24.3 \pm 3.9$ \\
\hline
\end{tabular}

74 people were found to be suffering from OSA as per polysomnographic criteria ( $\mathrm{AH}$ I $>5$ per hour of sleep) amongst the patients who came or were referred to PULSAR, the sleep laboratory in Kolkata, for evaluation of their symptoms suggestive of OSA during the period from D ecember 2000 - D ecember 2001. They were put to ESS questionnaire, scoring were done in specific situations and the total score were recorded individually. Scores $\geq 10$ and $<10$ were computed separately signifying "EDS" and "No ED S" group respectively. (Table 3).

Table 3: D ata showing ESS score of 74 persons having OSA $n=74$

\begin{tabular}{|l|l|l|}
\hline & $\begin{array}{l}\text { NO ED S } \\
(\text { ESS }<10)\end{array}$ & $\begin{array}{l}\text { ED S } \\
\text { (ESS } \geq 10)\end{array}$ \\
\hline$n$ & $14(18.9 \%)$ & $60(81.8 \%)$ \\
\hline M ale: Female & $11: 3$ & $57: 3$ \\
\hline
\end{tabular}

\section{Result}

ESS score of 737 randomly selected people (18 years and above) from Kolkata is summarized in Table II. They were put to "EDS" (ESS score $\geq 10$ ) and "No EDS" group (ESS score <10). 654 (88.7\%) persons were in "No EDS" and 84 (11.3\%) were in "ED S" group.

Table 3 shows ESS score of 74 polysomnographically diagnosed OSA patients (18 years and above) of Kolkata and were put to "ED S" and "N o EDS" group as before. $60(81.1 \%)$ were in "EDS" and $14(18.9 \%)$ were in "N 0 EDS" group.

To compare the percentage of control population having "EDS" (11.3\%) with corresponding percentage of "EDS" group of OSA people (81.1\%), we first calculate the Standard Error of Proportion of the control group. 
Table 4: Data showing gradation of OSA according to severity (as per AHI) and EDS and NO EDS group in each grade by ESS score

$\mathbf{n}=\mathbf{7 4}$

\begin{tabular}{|c|c|c|c|c|c|}
\hline \multicolumn{2}{|c|}{ Mild OSA (AHI 5 - 15 / hour) $n=4$} & \multicolumn{2}{|c|}{ M oderate O SA (AH I 15-30 / hour) $n=12$} & \multicolumn{2}{|c|}{ Severe 0 SA (AH I >30/hour) $n=58$} \\
\hline $\begin{array}{l}\text { NO EDS } \\
(\text { ESS }<10) \\
n=4(100 \%)\end{array}$ & $\begin{array}{l}E D S \\
(E S S \geq 10) \\
n=0(0 \%)\end{array}$ & $\begin{array}{l}\text { NO EDS } \\
\text { (ESS <10) } \\
n=2(16.67 \%)\end{array}$ & $\begin{array}{l}\text { EDS } \\
(E S S \geq 10) \\
n=10(83.33 \%)\end{array}$ & $\begin{array}{l}\text { NO EDS } \\
(\text { ESS }<10) \\
n=0(0 \%)\end{array}$ & $\begin{array}{l}E D S \\
(E S S \geq 10) \\
n=58(100 \%)\end{array}$ \\
\hline Male Female & Male Female & Male Female & Male Female & M ale Female & M ale Female \\
\hline 1 & $\mathrm{Nil}$ & $\mathrm{Nil}$ & $\mathrm{Nil}$ & $\mathrm{Nil}$ & 53 \\
\hline
\end{tabular}

Standard Error of Proportion $=\sqrt{ } \mathrm{pq} / \mathrm{n}$

Where $p=$ percentage of persons having EDS of control group

$$
\begin{aligned}
\mathrm{q}= & \text { percentage of persons having } \mathrm{N} O \text { ED S of control } \\
& \text { group } \\
\mathrm{n}= & \text { sample size of control group }
\end{aligned}
$$

So, $\sqrt{ } \mathrm{pq} / \mathrm{n}=\sqrt{ } 11.3 \times 88.7 / 737=\sqrt{ } 1.359=1.17$

$95 \%$ confidence limit $=2 \times 1.17=2.34$

Therefore, proportion of persons having EDS in control group is $11.3 \pm 2.34$.

O ur observed value of proportion of persons having ED $S$ in OSA patients is 81.1 which is much higher and very significant.

Table 4 summarizes the OSA severity. The mild OSA group $(n=4)$ has all 4 patients in "N O EDS" group $(100 \%)$. The moderate OSA ( $n=12$ ) has 10 patients in "EDS" group (83.33\%) and 2 patients in "NO EDS" group (16.67\%). The severe OSA $(n=58)$ has all 58 patients in ED S group (100\%).

\section{Discussion}

The population based controlled study of prevalence of ED S by ESS score as done in PU LSAR, Kolkata, the first sleep laboratory in Eastern India, reflects EDS of $11.3 \%$ of the population. EDS prevalence have wide variation in different report ( $20 \%$ in one survey in $\mathrm{K}$ arachi, Pakistan and $31 \%$ in one survey in US) ${ }^{11,12}$. The ESS score of polysomnographically diagnosed $(\mathrm{AHI}>5)$ OSA patient have $81.1 \%$ of patients with EDS in our study. As the proportion of persons having EDS in control group is $11.3 \pm 2.34$, which is much lower than the proportion of persons having EDS in OSA patients (81.1), we may conclude that EDS as calculated by ESS scorehas good predictive valuein assessing O SA patients. As polysomnography (PSG), the gold standard for OSA diagnosis, is costly and has a very limited availability, ED $S$ as calculated by ESS score may be used as a good screening tool for subsequent diagnosis of OSA by PSG. O ne study, conducted in AlIM S, N ew D elhi, concludes that patients with OSA has significant higher ESS score 13. H owever, a study form Michigan, USA concludes that ESS score may not reflect objective measure of sleepiness or sleep apnea ${ }^{14}$.

The present study al so shows that the moderate and severe OSA patients have more number of "EDS" ( $83.33 \%$ in moderate and $100 \%$ in severe cases) compared to mild OSA where all 4 patients were in the "N o ED S" group suggesting that ESS score has positive association with moderate to severe OSA cases. Vancouver sleep study center, British Colombia, has also similar view like us. They suggest that in OSA, ESS $>16$ was seen only in patients with moderate to severe disease ${ }^{15}$. So, from $\mathrm{O}$ ur study we can also conclude that OSA patients presenting with EDS by ESS score have more chance of having moderate to severe diseases.

\section{Authors affiliations}

Dr. D. J. Roy Consultant Pulmonologist

Dr. A. Bhattacharya Research fellow

Dr. A. G. Ghosal Consultant

Dr. R. K. Das Consultant

PULSAR (Pulmonary Lab/Clinic and Sleep Associated Research Centre) Kolkata, West Bengal, India

\section{References}

1. Diagnostic classification Steering Committee, Thorpy M J Chairman : The International Classification System of Sleep Disorders : Diagnostic and Coding Manual : American Sleep Disorder Association, Rochester MN, 1990

2. Partinen $\mathbf{M}$, Guileminault $\mathbf{C}$. Daytime sleepiness and 
vascular morbidity at seven year follow up in obstructive sleep apnea patients, Chest 1990; 97 (1): 27-32.

3. Whyte KF, Allen MB, Jeffery AA, Gould GA, Douglas NJ. Clinical features the sleep apnea/hypopnea syndrome. Q J Med 1989; 72 : 659-66.

4. Obstructive sleep apnea syndrome. In : American Sleep Disorder Association, eds. The International Classification of Sleep Disorders, Revised : Diagnostic and Coding Manual. Rochester, MN, American Sleep Association, 1997; pp. 5258.

5. Caples SM, Gami AS, Somers VK, O bstructive Sleep Apnea: Annals of Internal Medicine 2005; 142(3) : 187-197.

6. Johns MW, A new method for measuring daytime sleepiness : The Epworth Sleepiness Scale : Sleep 1991 $14(6): 540-545$

7. University of Meryland Medical Centre, 22S, G reene Street, Baltimore.

8. Sleep Centre Information, Florida Hospital.

9. American Academy of Sleep Medicine Task Force (1999). Sleep-related breathing disorders in adults : recommendations for syndrome definition and measurement techniques in clinical research : The Report of an American Academy of Sleep Medicine Task Force, Sleep 22, 667-689

10. John MW : Sleepiness in different situations measured by Epworth Sleepiness Scale, 1994, 17(8); 703-710.

11. Haqqee R, Hussain SF, Mujib M, Ahmad H R. A hospital based preliminary report on sleep disorderd breathing in Pakistani population. J Ayub Med Coll Abbottabad. 2002 14(3) 2-4.

12. Roth T, Roehrs TA : etiologies and sequele of excessive daytime sleepiness : Clin Ther 1996 : 18 (4) : 562-76.

13. Pradeep Kumar VG, Bhatia M, Tripathi M, Srivastiva AK, Jain S: O bstructive sleep apnea, A case controlled study, Neurol. India, 2003; 51:497-499.

14. Chervin RD, Aldrich MS: The Epworth Sleepiness Scale may not reflect objective measures of sleepiness or sleep apnea; Neurology 1999 Jan : 52(1) : 125-31.

15. The Vancover Sleep and Breathing Centre - Vancouver, British Colombia. 